\title{
Cholecystokinin in the Pathogenesis of Bulimia Nervosa
}

\author{
Helena Trebbau López, Rosa María Molina-Ruiz, Laura Reyes Molón, Marina Díaz-Marsá
}

Instituto de Psiquiatría y Salud Mental, Hospital Clínico San Carlos, Madrid, Spain.

Email: helentrebbau@gmail.com

Received January $27^{\text {th }}, 2011$; revised May 30 ${ }^{\text {th }}$, 2011; accepted July $12^{\text {th }}, 2011$.

\begin{abstract}
Objective: This review aims to describe the role of the hormone cholecystokinin (CCK) in the pathogenesis of bulimia nervosa $(B N)$, the perpetuation of this illness and the possibility of its use as a target for future therapeutic advances. Methods: Search for cholecystokinin AND bulimia nervosa in Pubmed Central, with no limits, identified 38 articles published up to the present date. Results: It is well established that CCK is altered in the pathogenesis of $B N$, and that its main role is in the perpetuation of the disorder rather than the cause of it. Discussion: Additional studies will be needed to further understand the mechanisms by which CCK regulates orexigenic pathways. If an orally active, longer acting analogue of CCK could be developed, it would be of significant interest as an appetite suppressant and a key adjuvant in the treatment of patients suffering from $B N$, particularly in refractory cases.
\end{abstract}

Keywords: Satiety, Cholecystokinin, Bulimia Nervosa

\section{Introduction}

Food is a complex act in which several factors intervene. At a biological level, feeding behaviour is determined by nutritional needs and mechanisms for regulating food intake. In addition to its nutricional function, food has the intrinsic capacity to alter mood and activate reward mechanisms that are key to ensure repetition of activities that are essential for survival of the individual and the species [1].

Psychological aspects, both personality traits and family dynamics, are very influential in the way of establishing the link with food and body image: individuals with Anorexia nervosa (AN) tend to have high constricttion of affect and emotional expressiveness, anhedonia and asceticism, whereas individuals with Bulimia nervosa (BN) tend to be more impulsive and sensation seeking. This dysphoric temperament may involve an inherent dysregulation of emotional and reward pathways, which also mediates the hedonic aspects of feeding, thus making these individuals vulnerable to disturbed appetitive behaviours [2].

Comorbid psychiatric conditions, like affective and anxiety disorders, substance abuse or personality disorders, and sociocultural factors (availability of food, eating habits determined by the regional economy and social standards of beauty) also seem to influence eating behaviour [3].

$\mathrm{BN}$, one of the most common and secretive of these disorders, is characterized by compulsive binge eating followed by compensatory efforts, usually vomiting or laxative abuse, in order to purge calories and avoid weight gain [4,5]. This disorder is usually a chronic illness, which has been related to physiological disturbances in many neuronal and endocrine systems, especially the satiety reflex. The mechanisms for controlling food intake involve a complicated interplay between peripheral systems (including gustatory stimulation, gastrointestinal peptide secretion and vagal afferent nerve responses) and central nervous system neuropeptides, such as cholecystokinin (CCK), corticotropin-releasing hormone, $\beta$-endorphin, vasopressin, oxytocin, leptin, neuropeptide Y (NPY) and peptide YY (PYY) [6,7] and monoamines like noradrenaline, serotonine and dopamine [8].

The central nervous system (CNS) receives and processes information from both the physiological state of the organism and the environmental conditions (eg. organoleptic characteristics of foods and the education about eating received by each individual), which reaches its integration into the hypothalamus where we can find the "satiety center" in the ventral-medial hypothalamus (paraventricular and ventromedial nuclei) and the "appetite 
center” in the lateral hypothalamus [1].

The molecular signals that stimulate eating are NPY, norepinephrine and ${ }^{\circledR}$-endorphin, while those producing an inhibition of these behaviours are melanocyte stimulating hormone, corticotropin-releasing hormone and serotonine. These all work within the CNS, while the peptides CCK, leptin and specific cytokines, act at a peripheral level. This multiplicity of biological systems involved in eating behaviour ensures proper maintenance of the body weight [9].

Neurotransmitters and neuropeptides are also involved in circuits related to reward and memory of food experiences. In this way, psychological experiences are connected with eating behaviour [10]. The mesolimbic dopaminergic pathway is involved in the development of these gratification behaviours by increasing the release of dopamine in the nucleus accumbens, which as a conesquence, perpetuates the behaviour. These processes are determinants for "food preferences". The increase in dopamine in the lateral hypothalamus tonically inhibits the search for food and eating, acting on D2 dopamine receptors, which in turn inhibit the production of dopamine in the nucleus accumbens [11]. The postprandial reward systems are anatomically linked with opioids [12]. This would explain the self-addiction model described in the pathophysiology of EDs [13].

CCK is one of the most important substances in controlling volume and size of meals because of its powerful satiating effect [12], being considered the main negative regulator of ingestion [14]. Its production takes place at a gastrointestinal and central level. Its secretion, stimulated mainly by fat intake, causes a sensation of fullness in the gastrointestinal system and central hypothalamic satiety sensation by direct action or mediated by leptin. Interestingly, there appears to be substantial evidence of blunting CCK meal-related release in the pathogenesis of $\mathrm{BN}$, producing less satiety effect when eating a meal [15]. This review will address the role of CCK, one of the key neuropeptides, involved in the perpetuation of the pathogenesis of bulimia nervosa.

\section{Cholecystokinin}

The peptide hormone CCK was discovered in 1928 by Ivy and Oldberg because of its ability to induce gallbladder contraction. Together with secretin and gastrin, CCK constitutes the classical gut hormone triad [16-18]. In addition to gallbladder contraction, CCK also regulates pancreatic enzyme secretion and growth, intestinal motility, inhibition of gastric secretion and satiety sig naling. CCK is, however, also a transmitter in central and intestinal neurons.

In humans, CCK gene is located on chromosome 3 and the processing of proCCK is cell specific. Hence, endo- crine cells contain a mixture of medium size CCKs, whereas neurons mainly release CCK-8. This cell-specific synthesis is essential for function in the different compartments of the body [17]. Two CCK receptors have been identified. Both are 7 transmembrane G-proteins which activate phospholipase $\mathrm{C}$ and consequently, via the intracellular cascade, activate protein kinase C. CCK-A (alimentary) receptors bind only sulphated CCK-8 peptides, whereas the CCK-B (brain or gastrin) receptors are less restrictive also binding non-sulphated CCK and gastrin peptides [17].

The CCK-A receptor mediates gallbladder contraction, relaxation of the sphincter of Oddie, pancreatic growth and enzyme secretion, delay gastric emptying and inhibition of gastric acid secretion. Moreover it promotes insulin secretion in response to glucose, a property also present in other gastrointestinal hormones such as gastric inhibitory peptide. In this way it participates in the digestion of nutrients and its posterior subsequent metabolism [10]. Because of its effect in producing pyloric constricttion and inhibition of gastric emptying, it contributes to bloating and produces sensation of fullness and satiety [19].

Vagotomy studies indicate that peripheral CCK induces satiety via CCK-A receptors located in the pyloric sphincter and afferent abdominal vagal branches $[17,20$, 21]. CCK-A receptors have also been found in the anterior pituitary, the myenteric plexus and areas of the midbrain. The stimulation of CCK-A receptors located on peripheral vagal nerve, causes a signal that, after being processed in the CNS, results in a decrease of food intake. This food-related information is initially transmitted to the solitary tract nucleus, a region of the brainstem that integrates afferent signals both from gustatory and the gastrointestinal tract. Then, this information is eventually transmitted to the hypothalamus and other areas of the basal forebrain [22].

The CCK-B (brain or gastrin) receptor is the predominant CCK receptor in the brain, but less is known about its role. They are located mainly in the nucleus of the solitary tract and area postrema of the brain, modulating also in this way, the response to anxiety and pain $[23,24]$. Mapping of CCK-sensitive sites also show that the medial pons and lateral medulla in the vicinity of the tractus solitarius nucleus, significantly suppresses food intake. CCK has also been identified within the CNS as a hypothalamic neuropeptide and it has been shown to suppress feeding behaviour whenexogenously applied into the lateral hypothalamus [16]. In fact, the hindbrain contains sufficient neural complexity to convert the afferent signal into a behavioural decision to stop eating because CCK inhibits food intake in chronic decerebrated rats [25].

The satiety response to fat is antagonized by serotonin 
blockage, suggesting that serotonin mediates this action of CCK, possibly through their 5HT2C receptors [26]. CCK has also behavioural effects by inducing postprandial sedation and sleep. Likewise, it has an antidopaminergic activity, which decreases the search and interest in food [10]. CCK also inhibits expression of orexigenic peptides in the hypothalamus and prevents stimulation of specialized neurons by ghrelin [18].

At a peripheric level, CCK has also been shown that in the pancreas it increases the proliferation of insulinproducing beta cells and reduces insulin-induced hyperphagia. Elevated CCK levels also decrease appetite and reduce intestinal inflammation caused by parasites and bacterial toxins [18]. Furthermore, post-meal CCK release has been found to correlate with subjective ratings of satiety [27]. This inhibitory effect is dose related; it does not show significant degree of tolerance and is relatively specific in that equivalent doses have less effect on water intake [25]. Regarding its effect in normal and obese subjects, CCK demonstrated to reduce food intake in both type of patients.

\section{Dysregulation of CCK in Bulimia Nervosa}

Different alterations have been described in BN disorders: decreased noradrenergic, serotoninergic and dopaminergic activity, reduced colecistoquinergic action and increased orexigenic action of PYY [28], suggesting that satiety is altered in patients with BN [1,12]. Hormones like leptin, glucocorticoids and sexual steroids are also altered [10].

In 1988, Liddle and Geracioti investigated the hypothesis that abnormalities in CCK secretion and satiety may occur in patients with BN. Their results showed that fasting CCK levels were similar in BN patients and controls (approximately 0.8 pmol per liter) [29]. After eating, however, mean peak plasma CCK levels increased to 4.1 $+/-0.9$ pmol per liter in normal controls but to only 2.1 $+/-0.2$ pmol per liter in patients with BN (p $\delta 0.5$ ). These results led to following studies which supported the initial hypothesis [30-39]. Thus, in BN patients, the postprandial release OF CCK is decreased, while in AN patients, both basal and food induced CCK, is normal or elevated [40]. This fact has also been also been observed in the elderly and may also explain their lower appetite [41].

They also described that gastric emptying at 1 hour is statistically slower in bulimic patients than in control subjects, which is also in agreement with following studies done in this area $[4,17,42,43]$. Gastric dilation typically occurs afterbinge-eating and becomes manifest in upper abdominal pain and sometimes in spontaneous vomiting [43]. Findings of enlarged gastric capacity in normal-weight bulimics led to the proposal that repeated binge eating leads to increased stomach capacity that in turn leads to delayed gastric emptying and blunted postmeal CCK release. These effects give rise to an attenuation of the normal post-meal satiety response and thereby promote further eating, thus completing the cycle [27].

Since the release of CCK is stimulated by the presence of food in the duodenum after it empties from the stomach, CCK release is therefore partly dependent on gastric emptying. The whole-gut transit time, measured by radioisotope techniques, has also been demonstrated to be significantly delayed in patients with eating disorders [43]. Therefore, the coexistance of delayed gastric emptying and blunted CCK release suggests, but does not prove, that attenuated CCK response is caused by the delayed entry of food in the duodenum. Studies by Rolls et al. (1997) also demonstrated that consuming a high-fat diet for 2 weeks results in an increase of daily food intake, increase hunger and an increase in postprandial CCK, suggesting that periods of overeating can lead to a blunted satiety response due to downregulation of CCK receptors, thus contributing to further overeating [44].

However, studies done by Devlin et al. (1997) found no correlation between gastric emptying and CCK release, suggesting that factors other than the rate of gastric emptying affect interindividual variability in post-meal release. Nevertheless, although not all studies have demonstrated statistical differences in gastric compliance with controls, it has been well established that patients with BN exhibit diminished sensitivity to gastric distention [5].

Finally, these multiple neuroendocrine and neurotransmitter changes found in ED patients can be explained by the nutritional hypothesis. This hypothesis proposes that a temporary reduction of the incorporation of calories accompanied by a loss of weight may cause substantial changes in the levels of certain neurotransmitters and hormones. However, the changes in the different neurotransmitter, neuroendocrine and neuropeptidergic systems, seems to get back to normal after weight recovery $[9,35,45]$. Therefore, these changes appear to be adaptations to a temporary state of starvation, rather than the cause of it $[35,45,46]$.

\section{Discussion}

The role of CCK in the pathogenesis of BN seems to be a very important factor in the perpetuation of the disease, since it is at this stage when the patient has most problems in preventing a "normal" meal to convert into a binge because of lack of physiological satiety feedback. The patient may continue to eat until physical pain of fullness stops her/him. The more distended the stomach is, the longer the patient can keep bingeing. The findings of slowed gastric emptying and of impaired gastric ac- 
commodation following food ingestion indicate that stomach function in BN is characterized by a reduction in meal-related gastric muscular activity. These results suggest that, in patients with $\mathrm{BN}$, the stomach might also be more easily distensible, perhaps as a result of repeated episodes of binge eating [5].

In fact, most of the neuroendocrine and neuropeptide alterations apparent during symptomatic episodes of ED tend to normalize after recovery $[35,46]$. This observation suggests that most of the disturbances are conesquences, rather than causes, of malnutrition and altered meal patterns [47]. There is, however, some controversy whether these alterations are secondary to the conesquences of psychological conflicts and nutritional deficit (by restriction or by the binge-purge cycle) or a way of "self-defence" by the organism to starvation [13]. The psychological aspects eventually produce a biological imprinting; therefore the biological, psychological and social issues are so involved that feed each other continuously, being the disease, the final result of this interaction [13].

Further research of these neuropeptide disturbances may shed light on why many people with ED cannot easily "reverse" their illness even after having normalized their eating habits [16]. Substantial psychological, social, and physiological disturbances are associated with EDs, and it has been very difficult to disentangle those factors that may result from the disturbed behaviour from the factors that may have predisposed individuals to, or precipitated the development of, the disorder [48] suggesting the need for prolonged treatment $[9,49]$.

Understanding the mechanisms by which CCK regulates orexigenic pathways in the body may lead to new strategies for controlling appetite-related disorders such as obesity and bulimia nervosa [18]. In 1973, Gibbs et al. discovered that exogenous CCK inhibits food intake. The effect was dose dependent and specific, i.e.; it mimicked the satiety induced by food and was not seen with other gut peptides then known [17,30,31,50,51]. The sulphated form of CCK-8 was found to be the most potent for inhibiting food intake [20]. Thus, the current mechanism of action appears to be activation of pyloric or vagal recaptors by CCK-8, which then produce a propagated action potential up the afferent vagal fibers to the first central synapse in the nucleus tractus solitarius. Activation of the "satiety pathway" also induces release of the hypothalamic neuropeptide CCK, with the final result being inhibition of food intake. In fact, using synthetic agonists of CCK for obese patients experimentally, have shown that blocking this satiety factor increases the size of the intake [52].

Unfortunately, despite encouraging results with CCK in test meal situations, there are significant obstacles to its therapeutic use. These include the inactivity of orally administered CCK, no evidence concerning safety of CCK when administered chronically, just little evidence about the ability of CCK to inhibit intake of preferred foods, and the lack of evidence concerning the efficacy of CCK to produce actual weight loss in humans. If an orally active, longer acting analogue of CCK could be developed, it would be of significant interest as an appetite suppressant and a key adjuvant in the multidisciplinary treatment of patients suffering from bulimia nervosa, particularly in chronic refractory cases $[18,25]$.

\section{REFERENCES}

[1] V. J. Turón Gil, “Trastornos de la Alimentación,” In: A. Nerviosa, Ed., Bulimia y Obesidad, Masson, Barcelona, 1997.

[2] W. Kaye, "Neurobiology of Anorexia and Bulimia Nervosa,” Physiology \& Behavior, Vol. 94, No. 1, 2008, pp. 121-135. doi:10.1016/j.physbeh.2007.11.037

[3] K. A. Halmi. "Eating Disorders in Females: Genetics, Pathophysiology, and Treatment," Journal of Pediatric Endocrinology \& Metabolism, Vol. 15, No. S5, 2002, pp. 1379-1386.

[4] D. Kruger, "Bulimia Nervosa: Easy to Hide But Essential to Recognize," Journal of the American Academy of Physician Assistants (AAPA), Vol. 21, No. 1, 2008, pp. 48-53.

[5] E. J. Zimmerli, B. T. Walsh, J. L.Guss, M. J. Devlin, H. R. Kissileff, "Gastric Compliance in Bulimia Nervosa," Physiology \& Behavior, Vol. 87, No. 2, 2006, pp. 441- 446. doi:10.1016/j.physbeh.2005.11.010

[6] S. U. Devaskar, "Neurohumoral Regulation of Body Weight Gain,” Pediatric Diabetes, Vol. 2, No. 3, 2001, pp. 131-144. doi:10.1034/j.1399-5448.2001.002003131.x

[7] U. F. Bailer and W. H. Kaye, "A Review of Neuropeptide and Neuroendocrine Dysregulation in Anorexia and Bulimia Nervosa," CNS \& Neurological Disorders Drug Targets Home Page, Vol. 2, No. 1, 2003, pp. 53-59. doi:10.2174/1568007033338689

[8] A. Capasso, C. Putrella and W. Milano, "Recent Clinical Aspects of Eating Disorders," Reviews on Recent Clinical Trials, Vol. 4, No. 1, 2009, pp. 63-69. doi:10.2174/157488709787047594

[9] L. Guelman, "Bases Neurobiológicas de los Trastornos de la Alimentación,” Psicofarmacology, Vol. 6, 2000. http://www.sciens.com.ar/tratadodepsiquiatria/titulos/psic o/pdf/Numero06-Nota02.pdf.

[10] R. Lablanca and J. C. Montero, “Capítulo V: Patogenia de la Obesidad,” In: J. C. Montero, Ed., Obesidad en el adulto, Editorial D\&P, Buenos Aires, 1997. pp: 85-122.

[11] B. G. Hoebel, P. Rada, G. P. Mark, M. Parada and M. Puig de Parada. "Hypothalamic Control of the Mesolimbic Reward System: PVN Galanin and LH Dopamine," Progress in Obesity Research, Vol. 7, No. 24, 1996, pp. 393-403. 
[12] C. Fuentealba and M. J. Leiva, "Trastornos Alimentarios. Obesidad y Trastornos de la Conducta Alimentaria,” 2011. https://www.ucursos.cl/medicina/2009/1/MPSIQUI5/2/m aterial_docente/previsualiza r?id_material=207760.

[13] A. Lopez Mato and A. Vieitez. "Trastornos de la Alimentación,” In: A. Lopez Mato, Ed., Psiconeuroinmunología II, Editorial Polemos, Buenos Aires, 2004.

[14] A. Lopez Mato and A. Vieitez. "Trastornos de la Alimentación,” In: N. Marchant and A. Monchablon, Eds., Tratado de Psiquiatría, Editorial Grupo Guía, Buenos Aires, 2005.

[15] D. C. Jimerson and B. E. Wolfe, "Neuropeptides in Eating Disorders," CNS Spectrums, Vol 9, No. 7, 2004, pp. 516-522.

[16] R. R. Schick, V. Schusdziarra, T. L. Yaksh and V. L. Go. "Brain Regions Where Cholecystokinin Exerts Its Effect on Satiety," Annals of New York Academy of Sciences, Vol. 713, 1994, pp. 242-254. doi:10.1111/j.1749-6632.1994.tb44072.x

[17] J. F. Rehfeld, “Cholecystokinin,” Best Practice \& Research Clinical Endocrinology, Vol. 18, No. 4, 2004, pp, 569-586.

[18] R. Chandra and R. A. Liddle, "Cholecystokinin," Current Opinion in Endocrinology, Diabetes \& Obesity, Vol. 14, No. 1, 2007, pp. 63-67. doi:10.1097/MED.0b013e3280122850

[19] J. Copari, "Alteraciones de los Mecanismos de Control del Apetito y la Saciedad,” Fundación Escuela para la formación y actualización en Diabetes y Nutrición. http://www.fuedin.org/actualizaciones/Nutricion/a06-11/a lteracion.html

[20] G. Smith and J. Gibbs, "Satiating Effect of Cholecystokinin,” Annals of the New York Academy of Sciences, Vol. 713, 1994, pp. 242-241. doi:10.1111/j.1749-6632.1994.tb19874.x

[21] P. H. Robinson, P. R. McHugh, T. H. Moran and J. D. Stephenson, "Gastric Control of Food Intake,” Journal of Psychosomatic Research, Vol. 32, No. 2, 1988, pp. 593606. doi:10.1016/0022-3999(88)90008-6

[22] A. Lopez Mato and P. Beretta "Endocannabinoides en Ingesta Saciedad y en Adicciones,” 2011. http://www.ipbi.com.ar/

[23] J. D. Rosamond, "FPL 15849KF: A Highly Selective CCK-A Agonist with Potent Anorectic Activity,” In: $L$. Weston and L Savage, Eds., Advances in Understanding and Treatment, Biomedical Library Series, 1995.

[24] M. Rosenbaum, R. L. Leibel and J. Hirsch, "Obesity," The New England Journal of Medicine, Vol. 337, 1997, pp. 396-407. doi:10.1056/NEJM199708073370606

[25] M. Winick. “Control of Appetite,” John Wiley \& Sons, Inc., New York, 1988.

[26] D. C. Jimerson, M. D. Lesem, A. P. Hegg and T. D. Brewerton, "Serotonin in Human Eating Disorders," Annals of the New York Academy of Sciences, Vol. 600, 1990, pp. 532-544. doi:10.1111/j.1749-6632.1990.tb16908.x
[27] M. Devlin, B. T. Walsh, J. L. Guss, H. R. Kissileff, R. A. Liddle and E. Petkova, "Postprandial Cholecystokinin Release and Gastric Emptying in Patients with Bulimia Nervosa," The American Journal of Clinical Nutrition, Vol. 65, 1997, pp. 114-120.

[28] Y. Takimoto, A. Inui, H. Kumano and T. Kuboki, "Orexigenic/Anorexigenic Signals in Bulimia Nervosa," Current Molecular Medicine, Vol. 3, No. 4, 2003. pp: 349-360. doi:10.2174/1566524033479762

[29] T. D. Jr. Geracioti and R. A. Liddle, "Impaired Cholecystokin Secretion in Bulimia Nervosa,” The New England Journal of Medicine, Vol. 319, 1988, pp. 683-688.

[30] T. D. Geracioti, M. A. Kling, J. R. Joseph-Vanderpool, S. Kanayama, N. E. Rosenthal, P. W. Gold, et al., "MealRelated Cholecystokinin Secretion in Eating and Affective Disorders,” Psychopharmacology Bulletin, Vol. 25, No. 3, 1989, pp. 444-449.

[31] H. Tamai, J. Takemura, N. Kobayashi, S. Matsubayashi, S. Matsukura and T. Nakagawa, "Changes in Plasma Cholecystokinin Concentrations after Oral Glucose Tolerance Test in Anorexia Nervosa before and after Therapy,” Metabolism, Vol. 42, No. 5, 1993, pp. 581-584.

[32] W. H. Kaye and T. E. Weltzin, "Neurochemistry of Bulimia Nervosa,” Journal of Clinical Psychiatry, Vol. 52, 1991.

[33] R. B. Lydiard, T. D. Brewerton, M. D. Fossey, M. T. Laraia, G. Stuart, M. C. Beinfeld, et al., "CSF Cholecystokinin Octapeptide in Patients with Bulimia Nervosa And in Normal Comparison Subjects,” American Journal of Psychiatry, Vol. 151, No. 7, 1994, p. 1098.

[34] K. M. Pirke, M. B. Kellner, E. Friess, J. C. Krieg and M. M. Fichter, "Satiety and Cholecystokinin," International Journal of Eating Disorders, Vol. 15, No. 1, 1994, pp. 63-69.

doi:10.1002/1098-108X(199401)15:1<63::AID-EAT2260 $150108>3.0 . \mathrm{CO} ; 2-\mathrm{V}$

[35] K. Wlodarczyk-Bisaga and A. Bisaga, "Selected Issues of Biological Aspects of Eating Disorders,” Psychiatria Polska, Vol. 28, No. 5, 1994, pp. 579-591.

[36] F. Brambilla, M. Brunetta, A. Draisci, A. Peirone, G. Perna, P. Sacerdote, et al., "T-Lymphocyte Concentrations of Cholecystokinin-8 and Beta-Endorphin in Eating Disorders: II. Bulimia Nervosa,” Psychiatry Research, Vol. 59, No. 1-2, 1995, pp. 51-56. doi:10.1016/0165-1781(95)02674-6

[37] D. C. Jimmerson and B. E. Wolfe, "Neuropeptides in Eating Disorders,” CNS Spectrum, Vol. 9, No. 7, 2004, pp. 516-522.

[38] P. K. Keel, B. E. Wolfe, R. A. Liddle, K. P. De Young and D. C. Jimerson, "Clinical Features and Psysiological Response to a Test Meal in Purging Disorder and Bulimia Nervosa," Archives of General Psychiatry, Vol. 64, No. 9, 2007, pp. 1058-1066. doi:10.1001/archpsyc.64.9.1058

[39] A. C. Prince, S. J. Brooks, D. Stahl and J. Treasure, "Systematic Review and Meta-Analysis of the Baseline Concentrations and Physiologic Responses of Gut Hormones to Food in Eating Disorders," The American 
Journal of Clinical Nutrition, Vol. 89, No. 3, 2009, pp. 755-765. doi:10.3945/ajen.2008.27056

[40] W. H. Kaye, W. H. Berrettini, H. E. Gwirtsman, P. W. Gold, D. T. George, D. C. Jimerson, et al., "Contribution of CNS Neuropeptide (NPY, CRH, and Beta-Endorphin) Alterations to Psychophysiological Abnormalities in Anorexia Nervosa," Psychopharmacology Bulletin, Vol. 25, No. 3, 1989, pp. 433-438.

[41] M. Fava, P. M. Copeland, U. Schweiger and D. B. Herzog, "Neurochemical Abnormalities of Anorexia Nervosa and Bulimia Nervosa," The American Journal of Psychiatry, Vol. 146, No. 8, 1989, pp. 963-971.

[42] S. J. Hadley and B. T. Walsh, "Gastrointestinal Disturbances in Anorexia Nervosa and Bulimia Nervosa," Current Drug Targets - CNS \& Neurological Disorders, Vol. 2, No. 1, 2003, pp. 1-9.

[43] S. Zipfel, I. Sammet, N. Rapps, W. Herzog, S. Herpertz and U. Martens, "Gastrointestinal Disturbances in Eating Disorders: Clinical and Neurobiological Aspects," Autonomic Neuroscience-Basic \& Clinical, Vol. 129, 2006, pp, 99-106.

[44] B. J. Rolls, M. M. Hetherington, S. A. Stoner and A. E. Andersen, "Effects of Preloads of Differing Energy and Macronutrient Content on Eating Behavior in Bulimia Nervosa,” Appetite, Vol. 18, 1997, pp. 26-33.

[45] F. Bramilla, "Aetiopathogenesis and Pathophysiology of Bulimia Nervosa; Biological Bases and Implications for Treatment,” CNS Drugs, Vol. 15, No. 2, 2001, pp. 119136.

[46] L. S. Usdan, L. Khaodhiar and C. M. Apovian, "The En- docrinopathies of Anorexia Nervosa," Endocrine Practice, Vol. 14, No. 8, 2008, pp. 1055-63.

[47] N. C. Barbarich, W. H. Kaye and D. Jimerson "Neurotransmitter and Imaging Studies in Anorexia Nervosa: New Targets for Treatment," Current Drug TargetsCNS \& Neurological Disorders, Vol. 2, No. 1, 2003, pp. 61-72. doi:10.3945/ajcn.2008.27056

[48] D. A. Klein and B. T. Walsh, "Eating Disorders: Clinical Features and Pathophysiology,” Physiology \& Behavior, Vol. 81, No. 2, 2004, pp. 359-374. doi:10.1016/j.physbeh.2004.02.009

[49] E. A. Lawson and A. Klibanski, "Endocrine Abnormalities in Anorexia Nervosa," Nature Reviews Endocrinology, Vol. 4, No. 7, 2008, pp. 407-414. doi:10.1038/ncpendmet0872

[50] A. L. Hirschberg, S. Naessén, M. Stridsberg, B. Byström and J. Holtet, "Impaired Cholecystokinin Secretion and Disturbed Appetite Regulation in Women with Polycystic Ovary Syndrome," Gynecological Endocrinology, Vol. 19, No. 2, 2004, pp. 79-87. doi:10.1080/09513590400002300

[51] E. Phillip, K. M. Pirke, M. B. Kellner and J. C. Krieg, "Disturbed Cholecystokinin Secretion in Patients with Eating Disorders,” Life Science, Vol. 48, No. 25, 1991, pp. 2443-2450. doi:10.1016/0024-3205(91)90379-P

[52] A. Márquez and A. Mato López, "Viejos y Nuevos Péptidos en los Trastornos de la Alimentación,” 2011. www.aapb.org.ar/act-cient/Viejos-nuevos-pepetidos-Kali na. doc 